\title{
Evaluation of PAH Contamination from Smoke in Smoked Fish Obtained from Northern Nigeria
}

\author{
Oko, O. J. ${ }^{1}$ and C. O. B. Okoye ${ }^{2}$ \\ ${ }^{1}$ Department of Chemical Sciences, Federal University Wukari, Nigeria \\ ${ }^{2}$ Department of Pure and Industrial Chemistry, University of Nigeria, Nsukka, Nigeria \\ Email: odibaoko@hotmail.com
}

\begin{abstract}
Atlantic mackerel (Scomber Scombrus) fish were collected from processors in parts of northern Nigeria. The PAHs in smoked and non smoked samples were extracted with a mixture of dichloromethane and hexane in the ratio of 3:1 then cleaned up in a column packed with alumina. The cleaned extract was analyzed with gas chromatograph (HP 6890) coupled to flame ionization detector (FID). The study revealed that the total PAH concentrations in the non smoked fish is $5.675 \mathrm{\mu gkg}^{-1}$ while the total PAH concentrationsin the smoked fishes were $17.965 \mathrm{\mu gkg}^{-1}$ (smoked semidried fish) and $20.150 \mathrm{kgkg}^{-1}$ (smoked dried fish) respectively. The \% PAH contamination levels from smoke in the smoked semi-dried fish was in the range of 20-94 while that for the smoked dried fish was in the range of 20-95. Indeno[1,2,3-cd]pyrene had the lowest contaminations from smoke in both the smoked semi-dried and smoked dried fish. Twelve of the sixteen listed USEPA PAHs had mean concentrations that were statistically significant between the smoked fish and non smoked fish $(\mathrm{p}<0.05)$. However, acenaphtylene, benz[a]anthracene, dibenz[a,h]anthraceneand indeno[1,2,3cd]pyrene which contaminated the fish were not significant statistically $(p>0.05)$. Generally, the smoked dried fish were more contaminated than the smoked semi-dried fish. Nevertheless, the smoked fish were within the recommended Food Standard Agency limits of $2 \mathrm{\mu gkg}^{-1}$ and $12 \mu \mathrm{gkg}^{-1}$ for benzo[a]pyrene and PAH4 respectively. Consumption of small quantities of smoked fish may not necessarily pose threat to health. The study also provided database on PAH in foods fromparts of northern Nigeria which could contribute to establishing Nigerian standards for PAH in foods.
\end{abstract}

Keywords: Benzo[a]pyrene, contamination levels, fish, polycyclic aromatic hydrocarbons, PAH4, smoked fish

\section{Introduction}

Nigeria as other nations across the world is experiencing lots of challenges in the environment. Polycyclic aromatic hydrocarbons (PAHs) are one class of organic compounds that have been found to pose health threat in the environment [1]. Polycyclic aromatic hydrocarbons result from incomplete combustion of materials in the environment such as garbage, petroleum products, coal, meat and tobacco[2]. PAH have been found in water, air, soil and traces in various food products[3]. Furthermore, food processing at high temperatures such as grilling, roasting, frying and smoking have been found to be major PAH source generators[3]. PAHs can be grouped depending their molecular weights. Generally, Benz[a]anthracene, benzo[b]fluranthene, benzo[k]fluoranthene, benzo[j]fluoranthene, benzo[e]pyrene, benzo[a]pyrene, benzo[g,h,i]perylene, dibenzo[a,h]anthracene, chrysene, cyclopenta[c,d]pyrene, indeno[1,2,3-cd]pyrene and anthracene have molecular weights which lie between 228-278 $\mathrm{g} / \mathrm{mol}[4]$. Fluoranthene and pyrene are classed as medium molecular weight PAHs which have Molecular weight of $202 \mathrm{~g} / \mathrm{mol}$ while naphthalene, acenaphthene, fluorene, anthracene and phenanthrene are low molecular weight PAHs having Molecular weights of $152-178 \mathrm{~g} / \mathrm{mol}$.

Smoked fish products are mostly consumed as food in Nigeria. However, smoked food products have been associated with cancer due to the presence of Polycyclic Aromatic Hydrocarbons. Infact it has been reported that close to $70 \%$ are usually eaten as food [5]. Cancer refers to a medical condition which brings about uncontrolled divisions of abnormal cells in a part of the body leading to the formation of malignant tissues.

Pollution indices have been employed in assessing ecological geochemistry[6].It has been shown that 
pollution indices is a tool for processing, analyzing and conveying environmental information to decision makers, managers, technicians and the public[7]. It is therefore necessary to quantify the level of smoke PAH contamination in smoked fish consumed in northern Nigeria to provide the required information about smoke PAH contribution to fish for the public and decision makers to ensure that the food does not pose threat to health of consumers.

\section{Materials and Methods}

\subsection{Study Site}

The samples were collected from five towns in northern Nigeria. They include Makurdi (Benue State), Lokoja (Kogi state), Lafia (Nassarawa state), Wukari, Jalingo (Taraba state). The sample locations are indicated in figure 1 below;

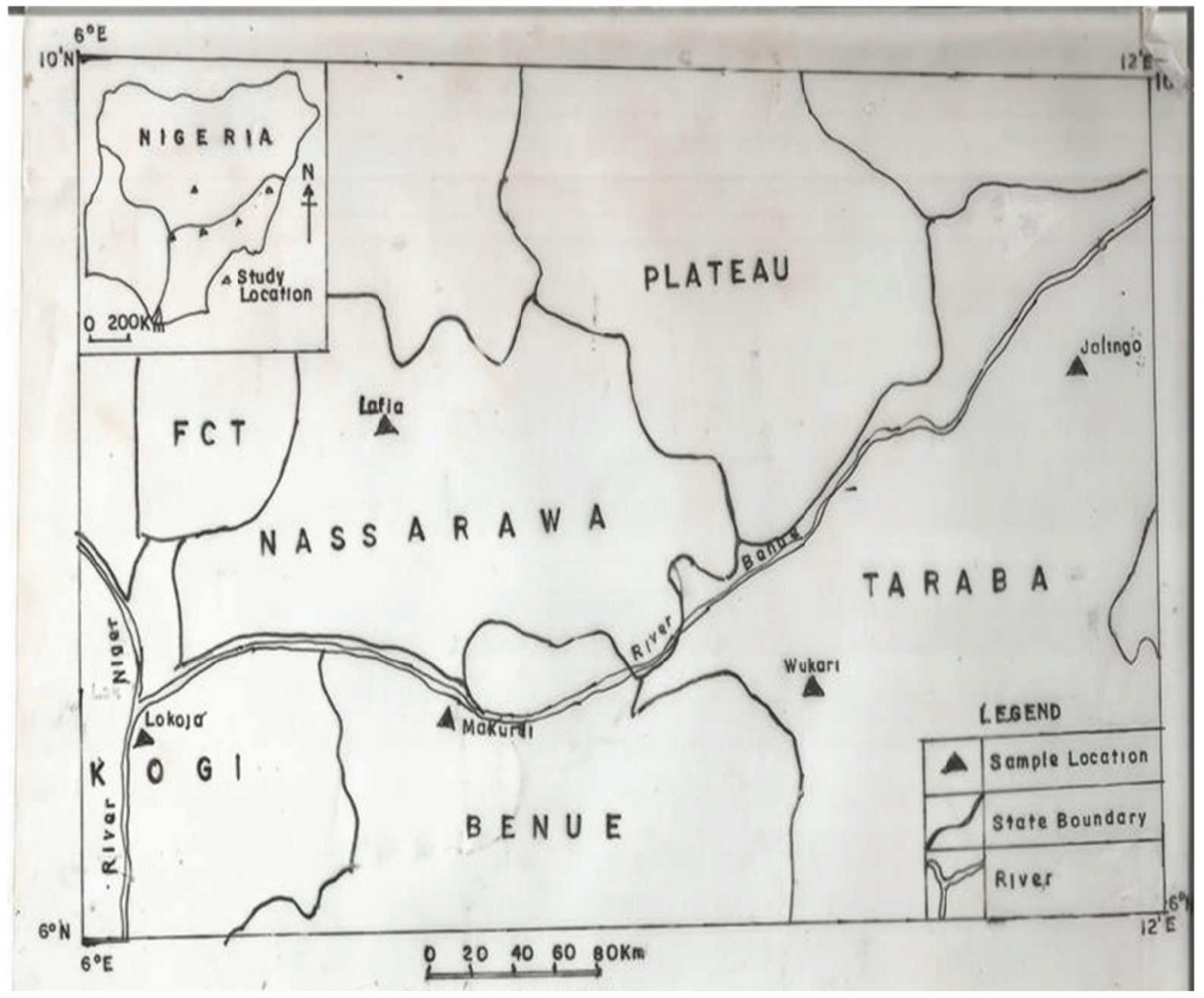

Figure 1. Map showing sample locations

\subsection{Reagents and Apparatus}

n-hexane (from Sigma Aldrich co., U.S.A), Dichloromethane (from British Drug House (BDH), England),Sodium Sulphate (from Aldrich-Chemie, Germany), Pure standard Mixture of 16 PAHs, Gas Chromatograph (Model:6890), Sonicator(Model:Julabo USR3) with frequency of $20 \mathrm{~Hz}$ and sonic power 50-200W, Oven (Genlab Model No: Mino/18) 


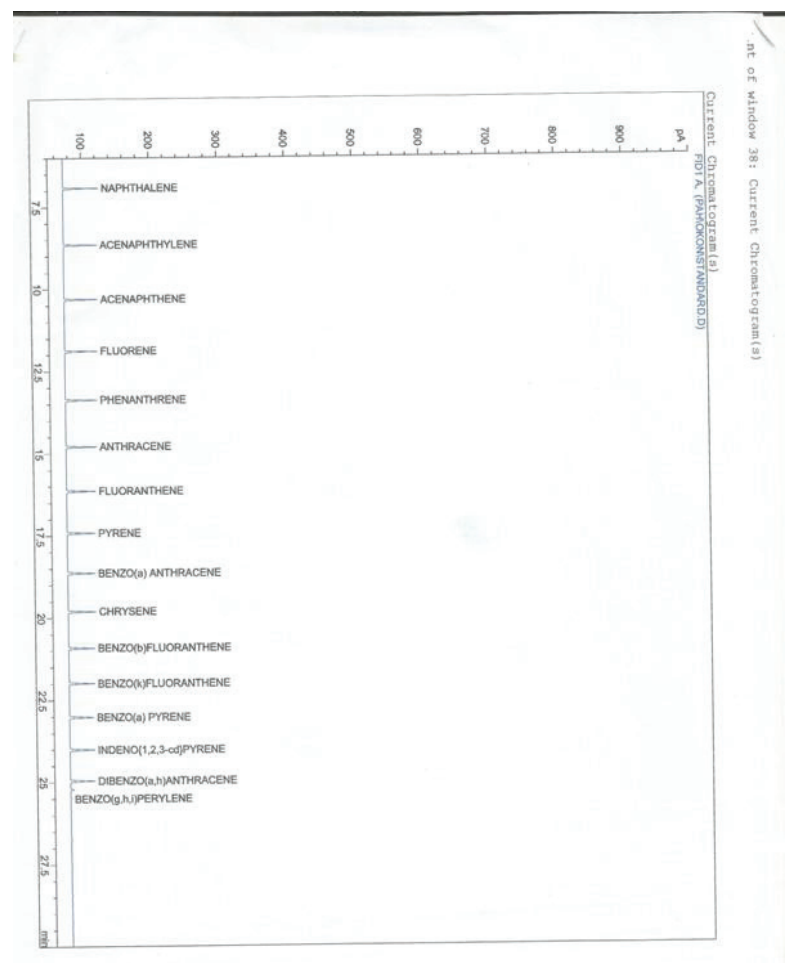

Figure 2. Chromatogram for pure PAH standard mix

\subsection{Sample Collection and Preparation}

Atlantic Mackerel (ScomberScombrus) fish was purchased randomly from the same processors in each of the five towns. Some of these were self processed by oven drying while the other parts were processed by processors as usually done for consumers. Two categories of smoked fish were processed. They include smoked semi-dried fish (which was smoked for about 1-2 hours) and the smoked dried fish (which was smoked for about 2-3 days). The study comprised fifteen (15) each of the smoked samples and five (5) samples of the non-smoked samples.

All the samples were placed in an oven(Genlab number: Mino/18) at $60^{\circ} \mathrm{C}$ and allowed to dry for two to three days, pulverized in a mortar with pestle and blended in a blender then put innon-transparent containers and properly labeled prior to extraction.

\subsection{Extraction of Polycyclic Aromatic Hydrocarbons from the Samples}

The extraction was carried out using modified method 3500C [8](USEPA, 2007).3.0g of the blended samples were weighed into a $250 \mathrm{ml}$ capacity beaker and $50 \mathrm{ml}$ of ratio $3: 1(75 \mathrm{ml}: 25 \mathrm{ml})$ redistilled hexanedichloromethane mixture added. The beaker and its content were placed in a Sonicator to extract the hydrocarbons for about 30 minutes. The organic layer was filtered into the $250 \mathrm{ml}$ capacity beaker and the extract dried by passing the filtrate through a funnel containing anhydrous Sodium Sulphate. The extract was then concentrated with a stream of nitrogen gas.

\subsection{Extract Clean Up}

Neutral alumina packed into a column up to $10 \mathrm{~cm}$ was cleaned with redistilled hexane then the extract was poured onto the alumina and allowed to run down with the aid of redistilled hexane to elute the aliphatic profiles into a pre-cleaned $20 \mathrm{ml}$ glass container.The aromatic fraction was eluted with a 3:1 mixture of hexane and dichloromethane to recover the non-polar PAH fractions but the most polar PAHs were recovered by eluting with dichloromethane into the pre-cleaned beaker.The mixture was 
concentrated to $1 \mathrm{ml}$ by a stream of nitrogen gas then gas chromatographic analysis coupled to flame ionization detector was performed on it.

\subsection{Conditions for the Gas Chromatograph}

Model: HP6890; Column: HP-1; Column length/column internal diameter/Column film: $30 \mathrm{~m}, 0.25$ m, $0.25 \mu \mathrm{m}$; Injection temperature: $250{ }^{\circ} \mathrm{C}$;

Detector temperature: $320{ }^{\circ} \mathrm{C}$; Detector: Flame ionization detector; Initial temperature: $60{ }^{\circ} \mathrm{C}$ for 5 min; First rate: $15{ }^{\circ} \mathrm{C} / \mathrm{min}$ for $14 \mathrm{~min}$ and maintained for $3 \mathrm{mins}$; Second rate: $10{ }^{\circ} \mathrm{C} / \mathrm{min}$ for 5 min and maintained for 4 mins; Mobile phase or carrier: Nitrogen; Nitrogen column pressure: 30 psi; Hydrogen pressure: 28 psi; Compressed air pressure: 32 psi.

\subsection{Determination of \% PAH Contamination Level from Smoke}

The \% PAH contamination level from smoke which was developed to assess the extent of contamination of PAH from the was calculated from

$\mathrm{C}_{\mathrm{ss}}=$ Concentration of PAH in smoked samples

$$
\% \mathrm{PCL}=\frac{C s S-C n s}{C s S} \times 100
$$

$\mathrm{C}_{\mathrm{ns}}=$ Concentration of PAH in non-smoked samples

\subsection{Statistical Analysis}

The data collected was analyzed for their mean values and standard deviations using MS excel software while analysis of variance (ANOVA) was analyzed using SPSS 17 software at $\mathrm{P}<0.05$. These analyses helped to determine the level of significant difference in the mean concentrations of the polycyclic aromatic hydrocarbons in the various samples. The post Hoc tests employed the use of Duncan multiple range tests which identified homogeneous subsets of means that are not different from each other [9].

\section{Results and Discussions}

Table 1. PAH concentrations $(\mu \mathrm{g} / \mathrm{kg})$ in non-smoked fish

\begin{tabular}{lll}
\hline PAH & Range & Mean \pm SD \\
\hline Naphthalene & $0.009-0.015$ & $0.011 \pm 0.002$ \\
Acenaphthylene & $0.040-0.129$ & $0.094 \pm 0.004$ \\
Acenaphthene & $0.039-0.080$ & $0.054 \pm 0.002$ \\
Fluorene & $0.063-0.098$ & $0.083 \pm 0.016$ \\
Phenanthrene & $0.161-0.515$ & $0.288 \pm 0.163$ \\
Anthracene & $0.177-1.955$ & $0.895 \pm 0.979$ \\
Fluoranthene & $2.168-3.546$ & $2.840 \pm 0.634$ \\
Pyrene & $0.407-2.571$ & $1.305 \pm 1.104$ \\
Benz[a]anthracene & $0.002-0.022$ & $0.013 \pm 0.010$ \\
Chrysene & $0.005-0.020$ & $0.011 \pm 0.008$ \\
Benzo[b]fluoranthene & $0.003-0.007$ & $0.005 \pm 0.002$ \\
Benzo[k]Fluoranthene & $0.003-0.010$ & $0.007 \pm 0.003$ \\
Benzo[a]pyrene & $0.005-0.068$ & $0.041 \pm 0.032$ \\
Indeno[1,2,3-cd]pyrene & $0.001-0.011$ & $0.004 \pm 0.004$ \\
Dibenz[a,h]anthracene & $0.005-0.033$ & $0.020 \pm 0.014$ \\
Benzo[g,h,i]perylene & $0.003-0.008$ & $0.006 \pm 0.002$ \\
\hline Total PAH & 5.675 & \\
\hline
\end{tabular}

The PAH concentrations $(\mu \mathrm{g} / \mathrm{kg})$ in non-smoked fish are presented in Table 1 . The non-smoked fish had the highest PAHs concentrations contributed by fluoranthene (2.840 \pm 0.634$)$ while indeno[1, 2, 3- 
cd]pyrene $(0.004 \pm 0.004)$ was the least concentrated PAH in the non-smoked fish. The other PAHs that were found in the fish in order of decreasing concentrations are pyrene (1.305 \pm 1.104$)$; phenanthrene $(0.288 \pm 0.163)$; acenaphthylene $(0.094 \pm 0.040)$; fluorene $(0.083 \pm 0.016)$; acenaphthene $(0.054 \pm 0.017)$; benzo[a]pyrene (0.041 \pm 0.032$)$; dibenz[a,h]anthracene $(0.020 \pm 0.014)$; benz[a] anthracene $(0.013 \pm 0.010)$; chrysene $\quad(0.011 \pm 0.008)$; naphthalene $(0.011 \pm 0.002) ; \quad$ benzo[k]fluoranthene $(0.007 \pm 0.003)$; benzo[g,h,i]perylene $(0.006 \pm 0.024)$ and benzo[b]fluoranthene $(0.005 \pm 0.002)$. The total mean polycyclic aromatic hydrocarbons content is $5.675 \mu \mathrm{g} / \mathrm{kg}$.

Table 2. Mean PAH concentrations $(\mu \mathrm{g} / \mathrm{kg})$ in smoked semi-dried fish samples $(\mathrm{n}=15)$

\begin{tabular}{lll}
\hline PAH & Range & Mean \pm SD \\
\hline Naphthalene & $0.005-0.346$ & $0.196 \pm 0.172$ \\
Acenaphthylene & $0.002-0.490$ & $0.160 \pm 0.194$ \\
Acenaphthene & $0.046-0.522$ & $0.307 \pm 0.246$ \\
Fluorene & $0.074-0.540$ & $0.335 \pm 0.231$ \\
Phenanthrene & $0.568-1.259$ & $0.990 \pm 0.319$ \\
Anthracene & $0.670-7.122$ & $3.341 \pm 3.018$ \\
Fluoranthene & $2.625-8.729$ & $7.111 \pm 2.553$ \\
Pyrene & $2.076-9.635$ & $4.958 \pm 3.789$ \\
Benz[a]anthracene & $0.051-0.466$ & $0.160 \pm 0.172$ \\
Chrysene & $0.022-0.233$ & $0.083 \pm 0.085$ \\
Benzo[b]fluoranthene & $0.009-0.031$ & $0.020 \pm 0.011$ \\
Benzo[k]Fluoranthene & $0.006-0.038$ & $0.024 \pm 0.016$ \\
Benzo[a]pyrene & $0.092-0.242$ & $0.180 \pm 0.077$ \\
Indeno[1,2,3-cd]pyrene & $0.001-0.008$ & $0.005 \pm 0.003$ \\
Dibenz[a,h]anthracene & $0.000-0.324$ & $0.082 \pm 0.123$ \\
Benzo[g,h,i]perylene & $0.001-0.020$ & $0.013 \pm 0.009$ \\
\hline Total PAH & 17.965 & \\
\hline
\end{tabular}

Table 3. Mean PAH concentrations $(\mu \mathrm{g} / \mathrm{kg})$ in smoked dried fish samples $(\mathrm{n}=15)$

\begin{tabular}{lll}
\hline PAH & Range & Mean \pm SD \\
\hline Naphthalene & $0.006-0.379$ & $0.229 \pm 0.1888^{*}$ \\
Acenaphthylene & $0.002-0.595$ & $0.259 \pm 0.027^{* *}$ \\
Acenaphthene & $0.038-0.518$ & $0.322 \pm 0.255^{*}$ \\
Fluorene & $0.084-0.685$ & $0.340 \pm 0.247^{*}$ \\
Phenanthrene & $0.666-1.747$ & $1.235 \pm 0.045^{*}$ \\
Anthracene & $0.808-7.804$ & $3.670 \pm 3.498^{*}$ \\
Fluoranthene & $2.999-9.833$ & $7.920 \pm 2.834^{*}$ \\
Pyrene & $2.515-10.789$ & $5.615 \pm 4.312^{*}$ \\
Benz[a]anthracene & $0.062-0.592$ & $0.196 \pm 0.223^{* *}$ \\
Chrysene & $0.029-0.064$ & $0.047 \pm 0.018^{*}$ \\
Benzo[b]fluoranthene & $0.010-0.037$ & $0.023 \pm 0.012^{*}$ \\
Benzo[k]Fluoranthene & $0.007-0.046$ & $0.030 \pm 0.020^{*}$ \\
Benzo[a]pyrene & $0.104-0.282$ & $0.200 \pm 0.008^{*}$ \\
Indeno[1,2,3-cd]pyrene & $0.001-0.009$ & $0.005 \pm 0.003^{* *}$ \\
Dibenz[a,h]anthracene & $0.007-0.087$ & $0.041 \pm 0.034^{* *}$ \\
Benzo[g,h,i]perylene & $0.006-0.023$ & $0.018 \pm 0.007^{*}$ \\
\hline Total PAH & 20.150 & \\
\hline
\end{tabular}

* Indicates that there were significant differences in the mean concentrations of the smoked and non-smoked fish $(\mathrm{P}<0.05)$

** Indicates that there were no significant differences in the mean concentrations of the smoked and non-smoked fish $(\mathrm{P}>0.05)$ 
The PAH concentrations $(\mu \mathrm{g} / \mathrm{kg})$ in the smoked semi-dried fish samples are presented in table 2 . The study revealed that fluoranthene $(7.111 \pm 2.553)$ has the highest concentration in the samples while Indeno[1,2,3-cd]pyrene $(0.005 \pm 0.003)$ is the least concentrated PAH. The other PAHs in decreasing

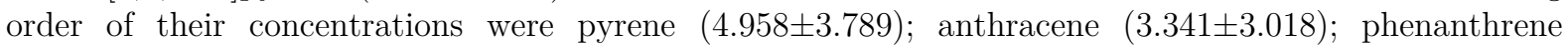
$(0.999 \pm 0.319)$; fluorene (0.335 \pm 0.231$)$; acenaphthene (0.3072 \pm 0.246$)$; naphthalene $(0.196 \pm 0.172)$; benzo[a]pyrene (0.180 \pm 0.077$)$; acenaphthylene $(0.160 \pm 0.194)$; benz[a]anthracene $(0.160 \pm 0.172)$; chrysene $(0.083 \pm 0.848) ; \quad$ dibenz[a,h]anthracene $\quad(0.082 \pm 0.123) ; \quad$ benzo[k]fluoranthene $\quad(0.024 \pm 0.016)$; benzo[b]fluoranthene $(0.020 \pm 0.011)$; benzo[g,h,i]perylene $(0.013 \pm 0.009)$;. The total mean concentration in the samples is $17.965 \mathrm{\mu g} / \mathrm{kg}$.

Similarly, the PAH concentrations $(\mathrm{\mu g} / \mathrm{kg})$ in the smoked dried fish samples are presented in Table 3 with fluoranthene $(7.920 \pm 2.834)$ having the highest concentration while indeno[1,2,3-cd]pyrene $(0.005 \pm 0.003)$ has the least concentration just like in the smoked semi-dried fish samples. The concentrations of the other PAHs in the samples include pyrene (5.615 \pm 4.312 ); anthracene (3.670 \pm 3.498$)$; phenanthrene (1.235 \pm 0.447$)$; fluorene (0.340 \pm 0.247$)$; acenaphthene $(0.322 \pm 0.255)$; acenaphthylene (0.259 \pm 0.027$)$; naphthalene $(0.229 \pm 0.188)$; benz[a]anthracene $(0.196 \pm 0.223)$; chrysene $(0.047 \pm 0.018) ; \quad$ dibenz[a,h]anthracene $\quad(0.041 \pm 0.034) ; \quad$ benzo[k]fluoranthene $\quad(0.030 \pm 0.020)$; benzo[b]fluoranthene (0.023 \pm 0.012$)$; benzo[a]pyrene $(0.200 \pm 0.085)$; benzo[g,h,i]perylene $(0.018 \pm 0.007)$. The total mean concentration of PAHs in the smoked dried samples is $20.150 \mu \mathrm{gg} / \mathrm{kg}$.

The \% PAH contamination levels from smoke to the smoked semi-dried fish and smoke dried fish respectively are presented in Table 4. This represents the contamination levels of each PAH from the smoke relative to its total contamination in the smoked sample. The results show that contaminations of most PAHs from smoke in the smoked semi-dried fish were greater than $50 \%$. They include naphthalene (94), fluorene (75), phenanthrene (71), anthracene (73), pyrene (74), benz[a]anthracene (92), chrysene (87), benzo[b]fluoranthene (75), benzo[k]fluoranthene (75), benzo[a]pyrene (77) and dibenz[a,h]anthracene (75), acenaphthene (64), fluoranthene (60) and benzo[g,h,i]perylene (54). However, acenaphthylene (41) and indeno[1,2,3-cd]pyrene (20) contamination levels was less than $50 \%$.

Table 4. \% PAH contamination levels from smoke in smoked semi-fish (SSF) and smoked dried fish samples

\begin{tabular}{lll}
\hline PAH & \% PCL (SSF) & \% PCL (SDF) \\
\hline Naphthalene & 94 & 95 \\
Acenaphthylene & 41 & 64 \\
Acenaphthene & 64 & 83 \\
Fluorene & 75 & 76 \\
Phenanthrene & 71 & 77 \\
Anthracene & 73 & 76 \\
Fluoranthene & 60 & 64 \\
Pyrene & 74 & 77 \\
Benz[a]Anthracene & 92 & 93 \\
Chrysene & 87 & 76 \\
Benzo[b]fluoranthene & 75 & 78 \\
Benzo[k]fluoranthene & 73 & 78 \\
Benzo[a]Pyrene & 77 & 80 \\
Indeno[1,2,3-cd]Pyrene & 20 & 20 \\
Dibenz[a,h]Anthracene & 75 & 50 \\
Benzo[g,h,i]perylene & 54 & 68 \\
\hline
\end{tabular}

The $\%$ contamination levels from the smoke to the smoked dried fish on the other hand were naphthalene (95), acenaphthene (83), fluorene (76), phenanthrene (77), anthracene (76), pyrene (77), benz[a]anthracene (93), chrysene (76), benzo[b]fluoranthene (78), benzo[k]fluoranthene (78) and benzo[a]pyrene (80), acenaphthylene (64), fluoranthene (64) and benzo[g,h,i]perylene (68) and dibenz $[\mathrm{a}, \mathrm{h}]$ anthracene (50). Indeno[1,2,3-cd]pyrene (20) from the smoke was however less than $50 \%$. 
Generally, it had been reported that average background values of PAHs in uncooked foods were usually in the range of $0.01-1.00 \mathrm{\mu gkg}^{-1}[10]$. This indicates that the values of most of the PAHs in this study were within this reported range. Furthermore, fish and marine invertebrates usually contain small or undetectable amounts of the different PAHs absorbed from the environment [11].A study done on catfish analyzed with HPLC showed that PAH contents recorded for oven dried samples were benzo[a]anthracene $\left(20.4 \mathrm{\mu gkg}^{-1}\right)$, benzo[a]pyrene (ND), benzo[b]fluoranthene (ND), benzo[k]fluoranthene (ND), chrysene $\left(8.9 \mathrm{\mu gkg}^{-1}\right)$, dibenz[a,h]anthracene $\left(50.9 \mathrm{\mu gkg}^{-1}\right)$ and benzo[g,h,i]perylene(ND)[3].The study had higher concentrations of benzo[a]anthracene, dibenz[a,h]anthracene and chrysene than the present study. However, concentrations of benzo[a]pyrene, benzo[b]fluoranthene, benzo[k]fluoranthene and benzo[g,h,i]perylene were not detected when compared with the present study which had traceable concentrations of these PAHs. Furthermore, in another study conducted on fresh catfish the PAHs concentration was found in ranges of $0.002-0.005 \mu \mathrm{gkg}^{-1}[12]$. These values were a little lower than the range of PAH concentrations determined for the present study. However, the total PAHs concentration determined in the present study is lower than total concentrations of $0.347 \mu \mathrm{gkg}^{-1}$ and $0.264 \mu \mathrm{gkg}^{-1}$ found for two fish species studied from western Nigeria [13]. Furthermore, in a study carried out on two fish species(Tilapia queneneesis and Liza falcipinis) from crude oil polluted waters in ogoniland gave total PAH concentration values of $17.7,84.7,121{\mu \mathrm{gkg}^{-1}}^{-}$and $20.6,79.2,96.9 \mathrm{\mu gkg}^{-1}$ respectively [1]. The values were higher than the results determined for fish which had no contact with smoke as in the present study. The PAH concentrations recorded in the fish before it was smoked may be attributed to other environmental sources such as the water source from which they were harvested from. In addition, deposition of PAHs from the air as a result of vehicular emissions as they were displayed could also be responsible. The scientific committee on food [14] had indicated in a report that food contamination by PAHs is usually through the air by deposition, from the soil by transfer or from water by deposition and transfer.

In the case of the smoked fish samples, it has been reported that benzo[a]pyrene in market samples of smoked fish obtained in western Kenya and analyzed by HPLC had concentrations in the range of 7.46 $\operatorname{\mu gkg}^{-1}-18.79 \mathrm{\mu gkg}^{-1}[15]$. The concentration ranges for B[a]p in the Kenya samples were however higher than that of the present study. Furthermore, a study carried out on Lates Niloticus samples obtained from Uganda showed that the sum of PAH4 was in the range of 8.14-11.00 [16]. These values were also higher than the values obtained for the present study.

Table 5. Mean concentration of $\mathrm{B}[\mathrm{a}] \mathrm{P}$ and $\sum \mathrm{PAH} 4$ concentrations $(\mathrm{\mu g} / \mathrm{kg})$ in smoked fish samples

\begin{tabular}{llll}
\hline Sample & SMOKED SEMI-DRIED FISH & SMOKED DRIED FISH & NON SMOKED FISH \\
\hline Benzo[a]pyrene & 0.1804 & 0.2003 & 0.0407 \\
EPAH4 & 0.4432 & 0.4668 & 0.0701 \\
\hline
\end{tabular}

The \% PAH contamination levels for the smoked semi-dried and smoked dried fishes corroborated the fact that PAHs from smoke contaminated the fish in measures greater than $50 \%$ except in the case of acenaphthylene and indeno[1,2,3-cd]pyrene. The reason for which is not clear. Generally, the smoked dried fish were more contaminated by most PAH than the smoked semi-dried fish. This shows that contamination depends on time of exposure to the source of PAHs. Naphthalene has been indicated to be a very harmful compound consequent upon its cytotoxic effects [17]. The study revealed $94 \%$ and $95 \%$ contamination of the PAH from smoke in the smoked semi-dried and smoked dried fish which is a pointer to the fact that naphthalene contaminated the smoked fish highly.

The PAHs are lipophilic (mixing easily with fats than water) and lipophilicity increases with increasing molecular mass [18]. This suggests that the PAHs may have had higher concentrations in the fish because of the high fat content and the mechanism of contamination is basically by absorption and not adsorption. Furthermore, the study also revealed that some of the PAHs contaminated the fish more from the smoke than the contributions made from other environmental sources. Generally, benzo[a]pyrene and the $\sum$ PAH4 in the non-smoked and smoked fish samples were within the acceptable limits of $2 \mu \mathrm{g} / \mathrm{kg}$ and $12 \mu \mathrm{g} / \mathrm{kg}$ as stipulated by the Food Standard Agency[19].

The analysis of variance (ANOVA) is a statistical tool employed to compare the means of a set of three groups. The ANOVA was used to compare the means of individual PAH in the non smoked fish, 
smoked semi-dried fish and smoked dried fish to ascertain if there were significant differences in their mean concentrations. The analysis revealed that there were significant differences in the mean concentrations of naphthalene, acenaphthene, fluorene, phenanthrene, anthracene, fluoranthene, pyrene, chrysene, benzo[b]fluoranthene, benzo[k]fluoranthene, benzo[a]pyrene and benzo[g,h,i]perylene at $\mathrm{p}<0.05$ except acenaphthylene, benz[a] anthracene, dibenz[a,h]anthracene and indeno[1,2,3-cd]pyrene whose mean concentrations were not statistically significant $(\mathrm{p}>0.05)$. The statistics show that for those with significant differences, the differences lied between the smoked semi-dried fish and non-smoked fish on one side and the smoked dried fish and non-smoked fish on the other side. Essentially, there were significant differences in means of these PAHs between the smoked fish and non-smoked fish.

\section{Conclusion}

Smoking is a common preservative measure embarked upon by most food processors in Nigeria. The study has revealed that preservation of fish by smoking contributes PAHs to the fish with contamination levels greater than $50 \%$ for most of the PAHs except acenaphthylene and indeno[1,2,3cd]pyrene in the smoked semi-dried fish and indeno[1,2,3-cd]pyrene in the smoked dried fish which had contamination levels below 50\%.Furthermore, the environment from which the fish is obtained prior to smoking also contributes some PAH to the fish thus each of the sixteen listed USEPA PAHs had PAH contributions from the environment in the smoked fish. The smoke however contributed more of each $\mathrm{PAH}$ to the fish than the environment and the contamination from smoke to fish was presumed to be generally by absorption rather than adsorption. Smoke screen iron boxes can be fabricated and used to prepare fish rather than exposing them directly to smoke or flame.

\section{References}

1. Nkpaa, K.W., Wegwu, M.O and Essien,B.E. (2013) Assessment of polycyclic aromatichydrocarbons (PAHs) levels in two commercially important fish species from crude oil polluted waters of ogoniland and their carcinogenic health risks. Journal of Environment and Earth Science. 3 (8):128-137.

2. Lau, E.V., Gan, S and Ng, H.K (2010) Extraction techniques for polycyclic aromatichydrocarbons in soil. International Journal of Analytical Chemistry.pp1-9

3. Silva, B.O., Adetunde, O.T., Oluseyi, T.O., Olayinka, K.O and Alo, B.I (2011) Effects of the methods of smoking on the levels of polycyclic aromatic hydrocarbons (PAHs) in some locally consumed fishes in Nigeria. African Journal of Food Science. 5(7): 384-391.

4. Palm, L.M.N., Carboo, D., Yeboah, P.O., Quasie, W.J., Gorleku, M.A and Darko, A. (2011)Characterization of Polycyclic Aromatic Hydrocarbons(PAHs)Present in smoked Fish from Ghana. Advance Journal of Food Science and Technology, 3(5):332-338.

5. Nnaji,J.C and Ekwe,N.P.(2018) Effect of smoking on Polycyclic Aromatic Hydrocarbons(PAHs) concentration in catfish and Tilapia muscles. Journal of Applied Sciences and Environmental management, 22 (2):293-297

6. Qingjie, G., Jun, D., Yunchuan, X., Qingfei, W and Liqiang, Y.(2008) Calculating pollution indices by heavy metals in ecological geochemistry assessment and a case study inparks of Beijing. Journal of China University of Geosciences. 19(3):230-241.

7. Caeiro,S., Costa,M.H., Ramos,T.B., Fernandes,F., Silveira,N., Coimbra,A., Medeiros,G and Painho, M. (2005) Assessing heavy metal contaminations in Sado estuary sediment: Anindex analysis approach. Ecological indicators. 5(2):151-169.

8. USEPA (2007) Method 3550C, Ultrasonic extraction. http://www.3.epa.gov/epawaste/hazard/testmethods/ SW846/pdfs/3550C.pdf.

9. Adetifa, F.A. and Ojikutu, R.K. (2009): Prevalence and trends in breast cancer in Lagos state, Nigeria. African Research Review, 3(5): 1-15.

10. FAO/WHO (2004) Discussion paper on polycyclic aromatic hydrocarbons (PAH)contamination. Joint FAO/WHO food standards programme. CODEX COMMITTEEON FOOD ADDITIVES AND CONTAMINANTS $37^{\text {th }}$ Session. Netherlands: pg1-9

11. Stolyhwo, A. and Sirkorski, Z. E. (2005) Polycyclic AromaticHydrocarbons in smoked fish: A critical Review. Food Chem, 91:303-311. 
12. Kafeelah.A.Yusuf., Lucy. N.Ezechukwu., Kafiyat.A.Fakoya., Shehu.L.Akintola., Julius.J.Agboola and Titus.O.Omoleye (2015) Influence of fish smoking methods onpolycyclic aromatic hydrocarbons content and possible risks to human health. African Journal of Food Science. 9(3):126-135.

13. Olabemiwo, O.M., Alade, A.O., Tella, A.C and Adediran, G.O.(2011) Assessment ofpolycyclic aromatic hydrocarbons content in smoked C.gariepinnus and T.guineensisfish species available in western Nigeria. International Journal of Basic and Applied Sciences. 11 (2):113-118.

14. Scientific committee on food (December,2002) polycyclic aromatic hydrocarbons-occurrence in foods, dietary exposure and health effects. http://europa.eu.in/comm./food/fs/sc/scf/index_en.html

15. Muyela, B., Shitandi, A. and Ngure, R. (2012): Determination of Benzo[a]pyrene levels in smoked and oil fried latesniloticus. International Food Research Journal, 19(4): 1595-1600.

16. Ongwech, A., Nyakairu, G. W., Mbabazi, J., Kwetegyeka, J. and Masette, M. (2013): Polycyclic Aromatic Hydrocarbons in smoked Latesniloticus from selected markets, Gulu district, Uganda. African Journal of Pure and Applied Chemistry, 7(4):164-172.

17. Verma, A., Meena, R., Maurya, A., Gaharwar, U.S and Rajamani, P.(2019) Identification, quantification and invitro genotoxicity of major polyaromaticHydrocarbons produced by Sugarcane. Journal of Environmental protection, 10:1244-1261

18. Eisler, R. (1987) Polycyclic Aromatic Hydrocarbon hazards to fish, wildlife and invertebrates: A synoptic review. Contaminant hazard reviews report No11

19. Food standard agency (2012) polycyclic aromatic hydrocarbons in cereals, cereal products, vegetables, vegetable products and traditionally smoked foods. Food survey information sheet.

\section{Appendix}

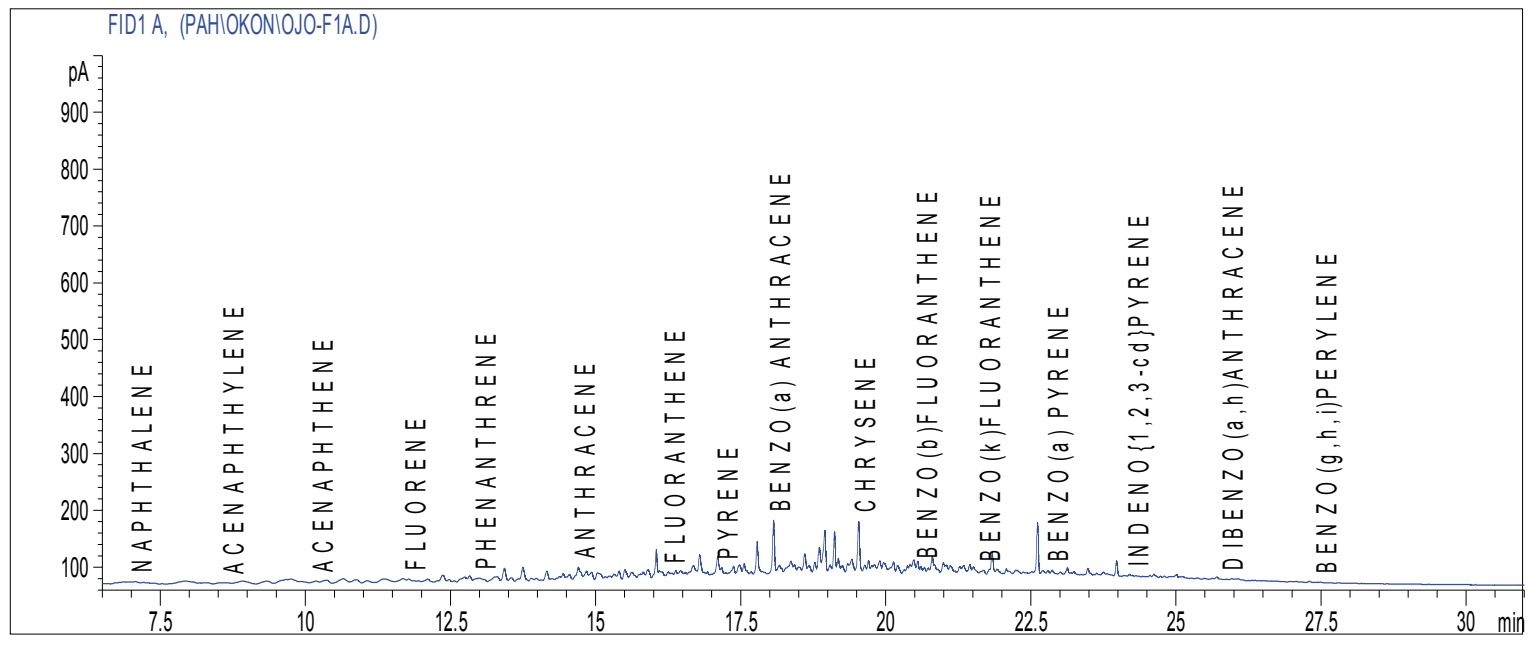

Figure 3. Chromatogram for semi smoked fish from Lokoja 


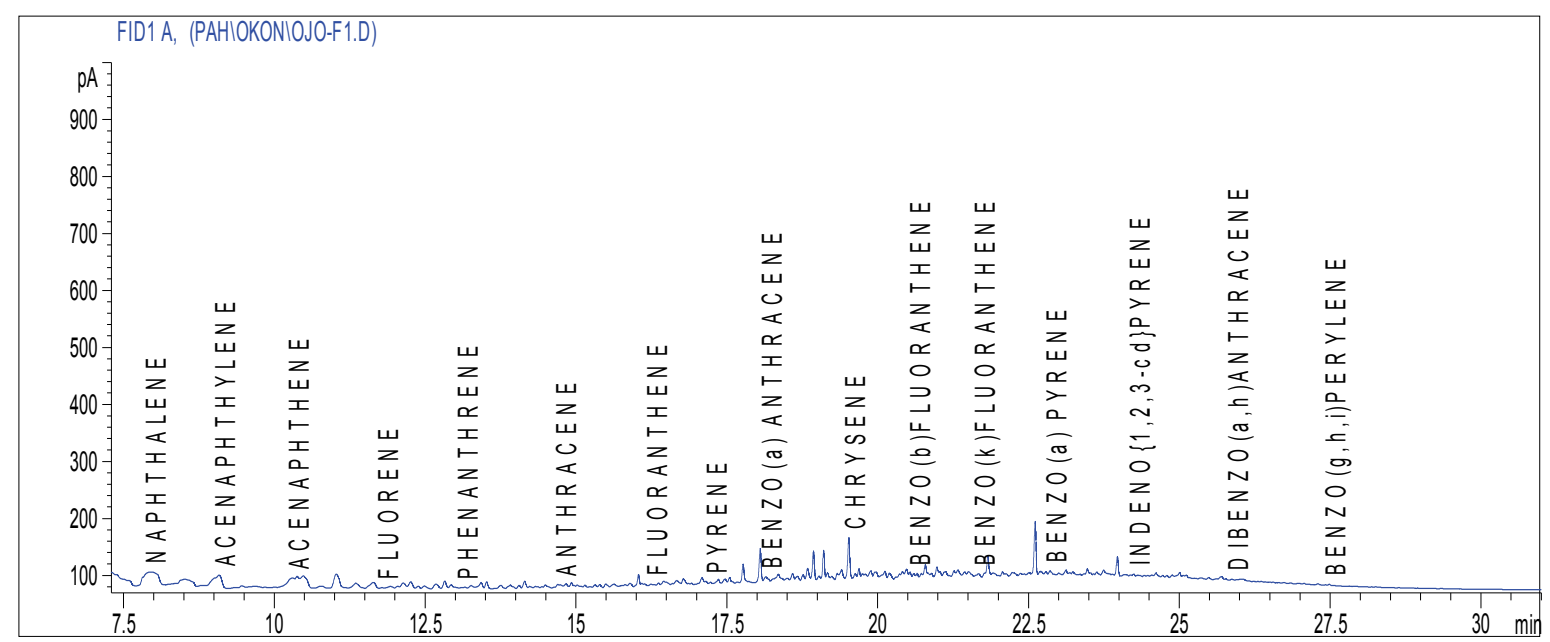

Figure 4. Chromatogram for semi smoked fish from Wukari

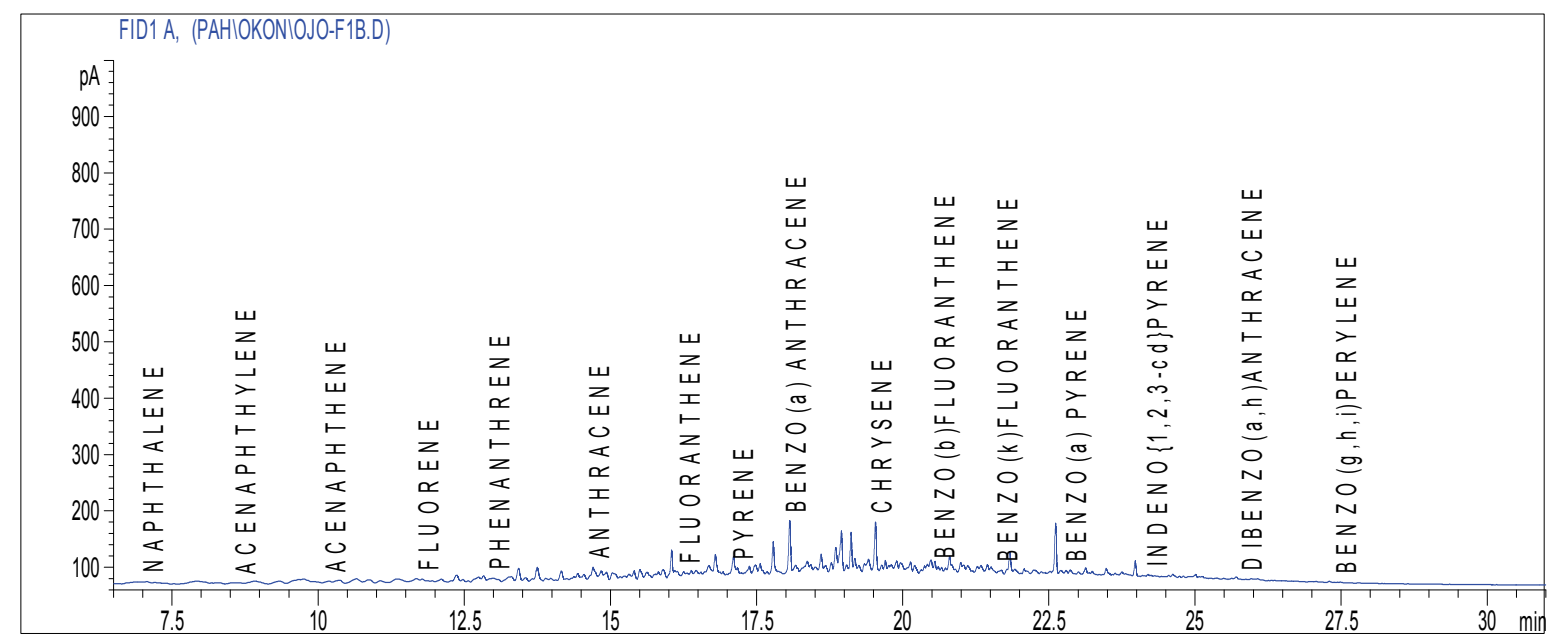

Figure 5. Chromatogram for semi smoked fish from Jalingo

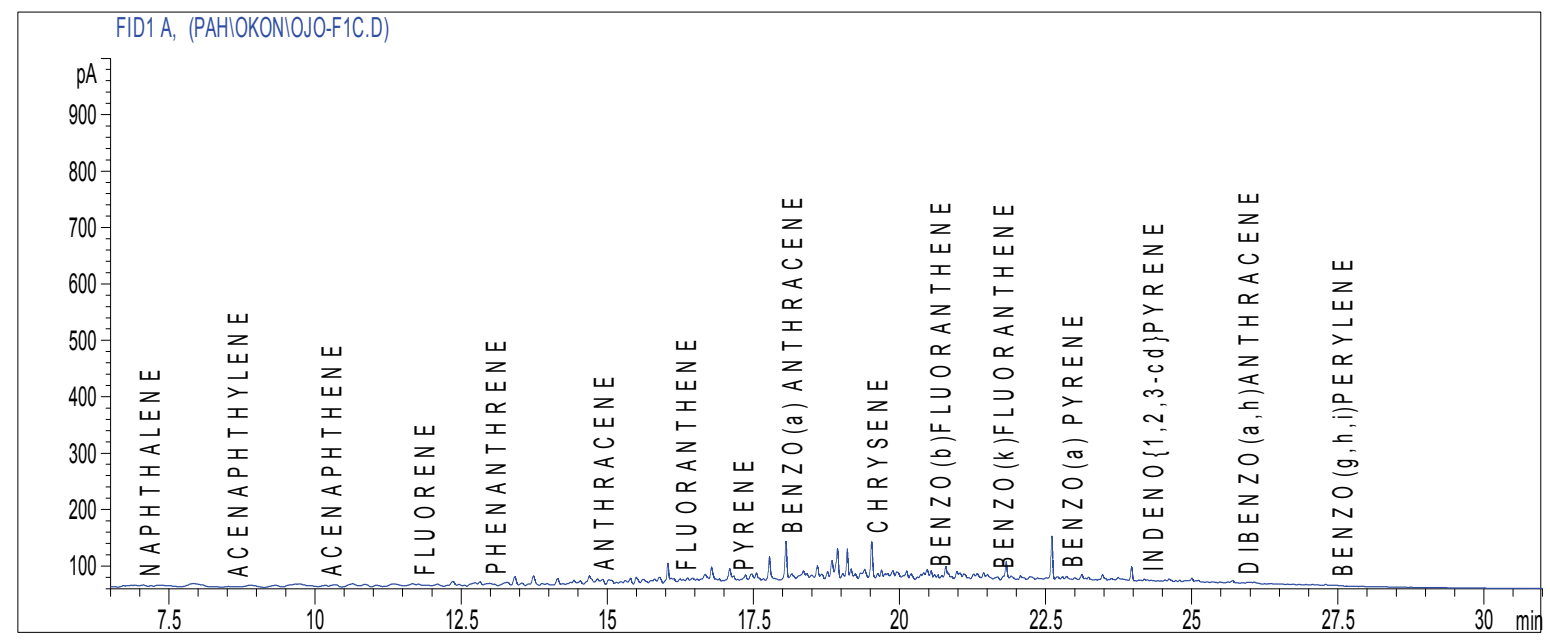

Figure 6. Chromatogram for semi smoked fish from Lafia 


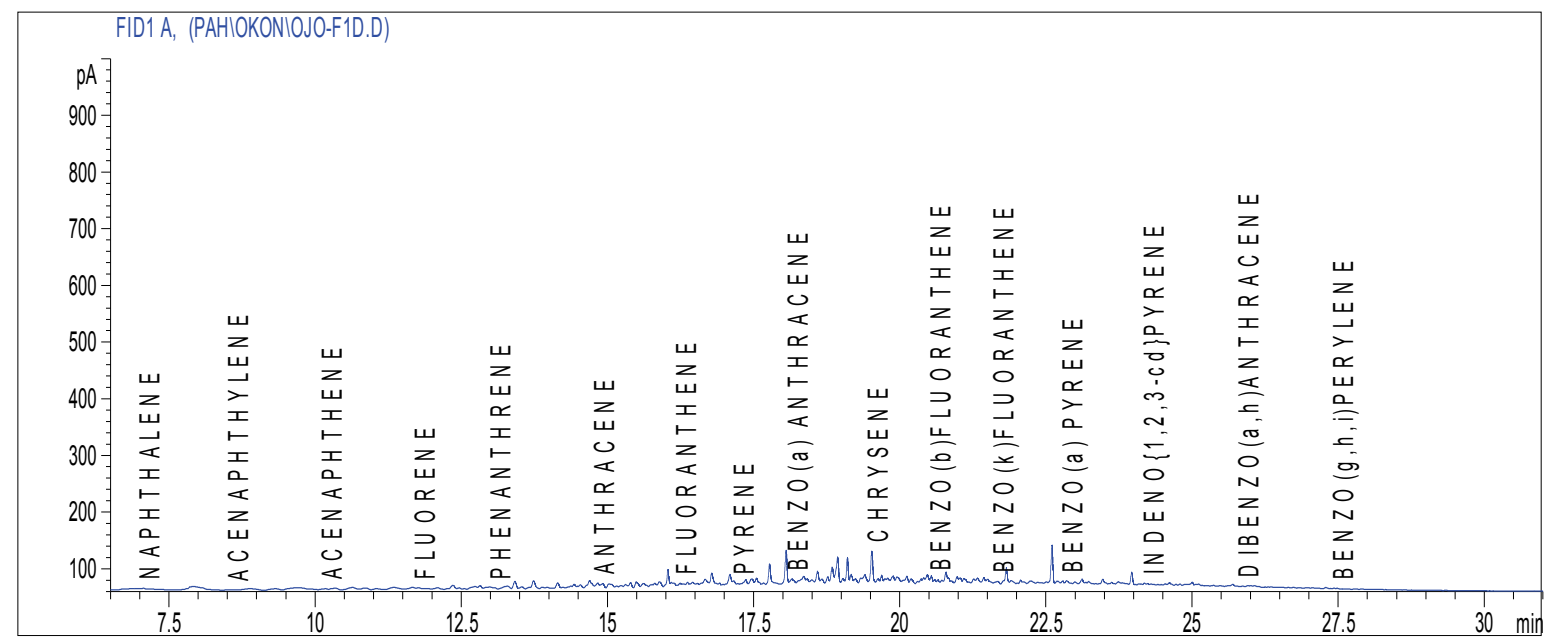

Figure 7. Chromatogram for semi smoked fish from Makurdi

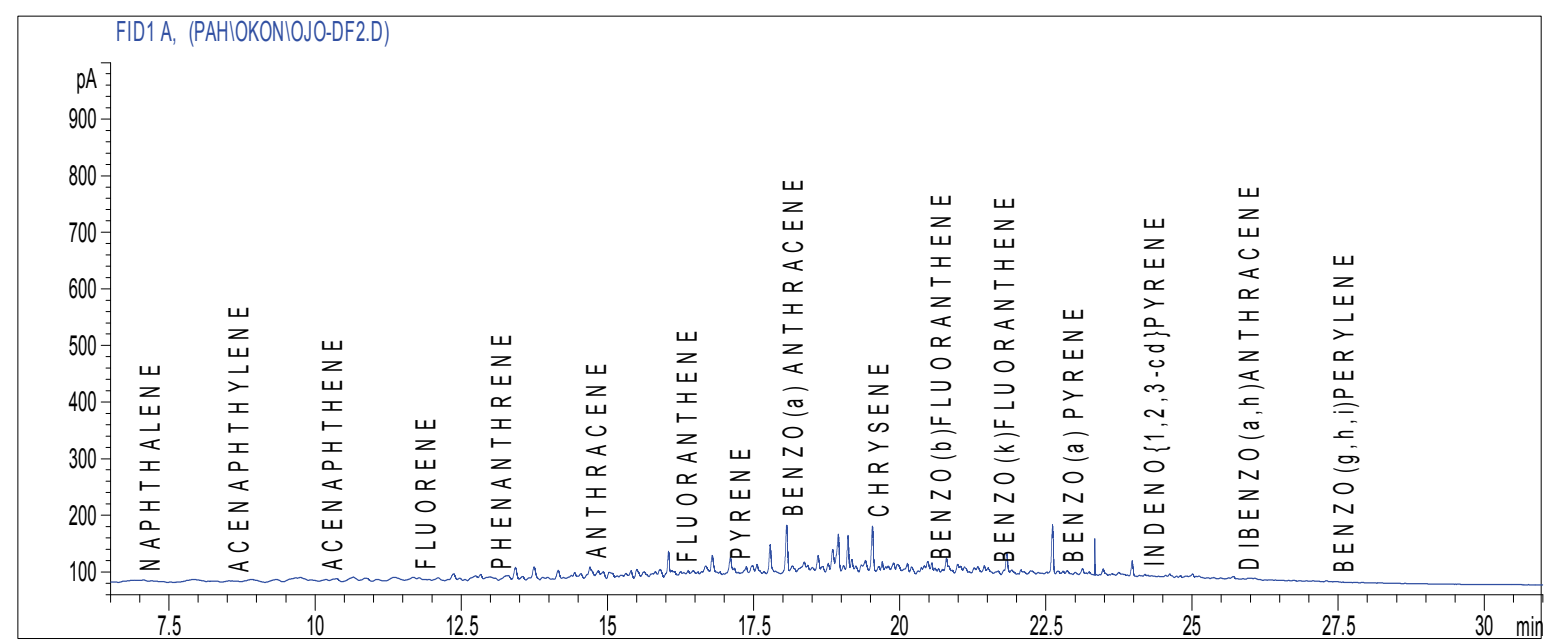

Figure 8. Chromatogram for smoked dried fish from Wukari

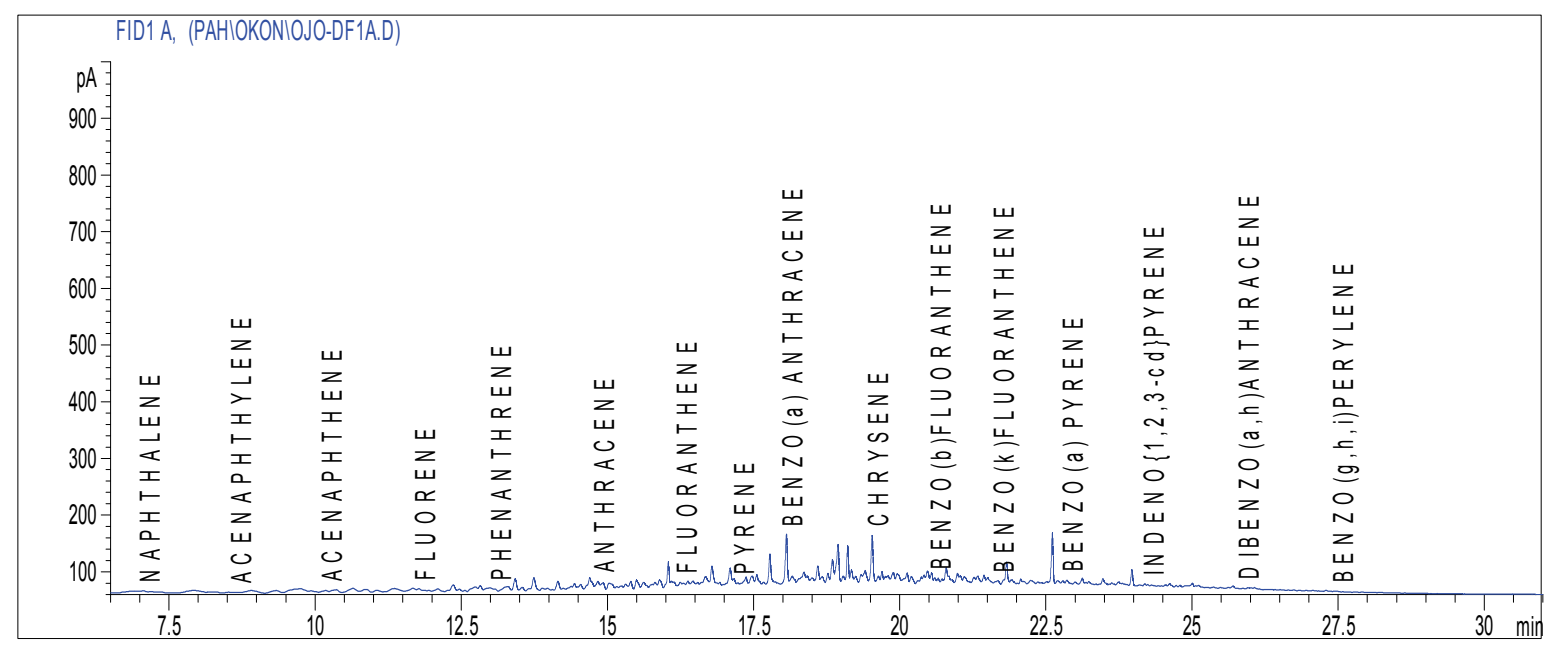

Figure 9. Chromatogram for smoked dried fish from Lokoja 


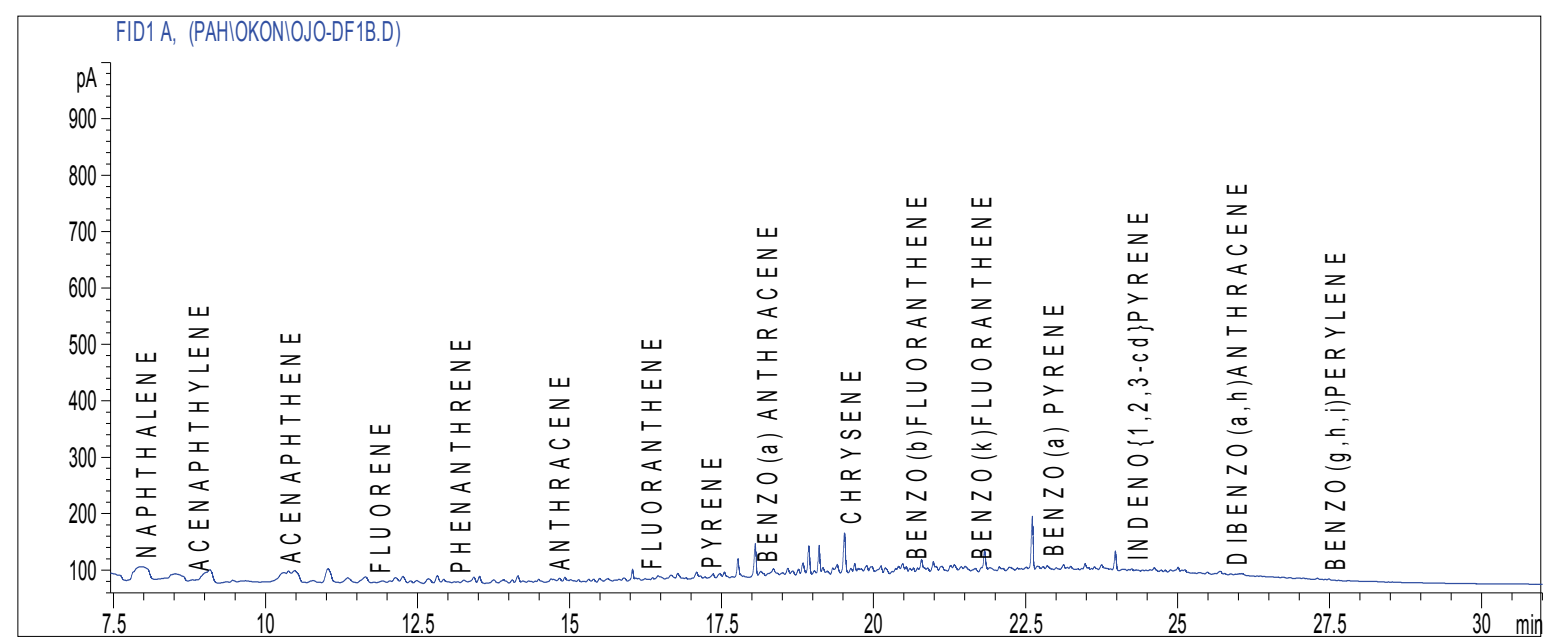

Figure 10. Chromatogram for smoked dried fish from Jalingo

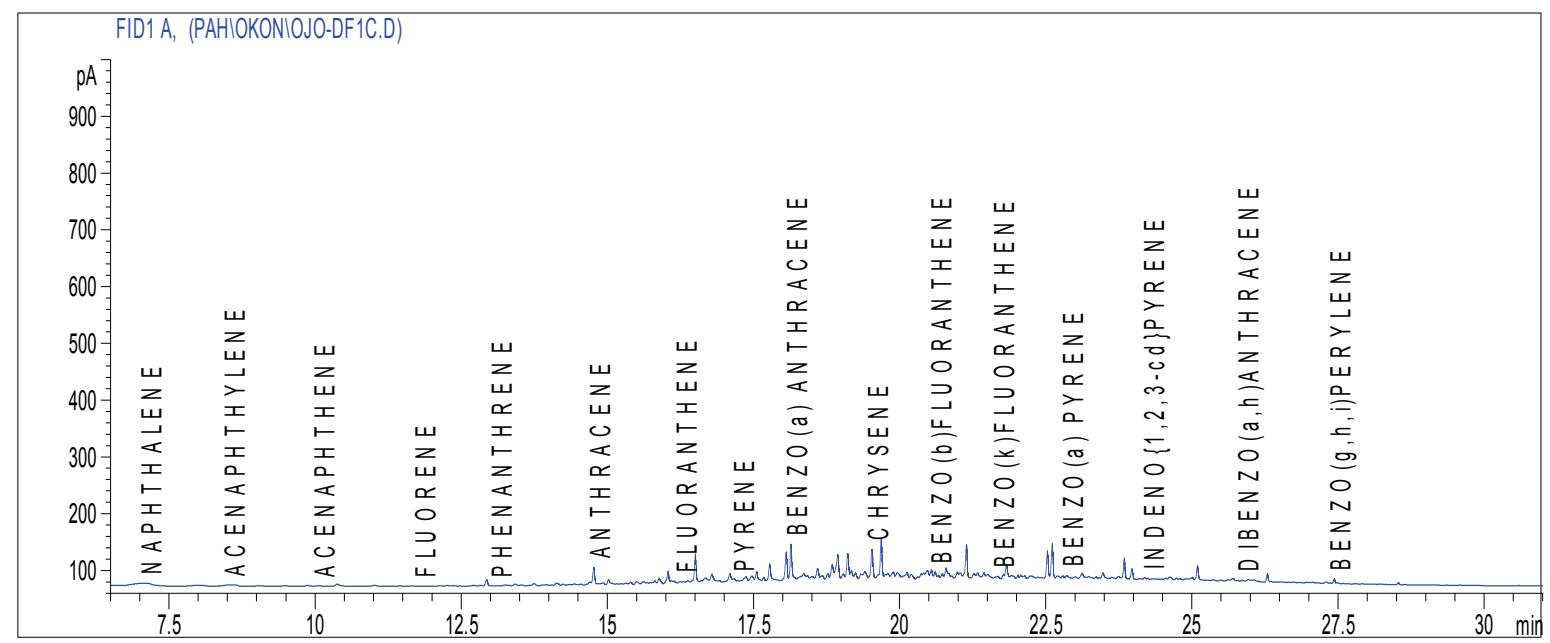

Figure 11. Chromatogram for smoked dried fish from Lafia

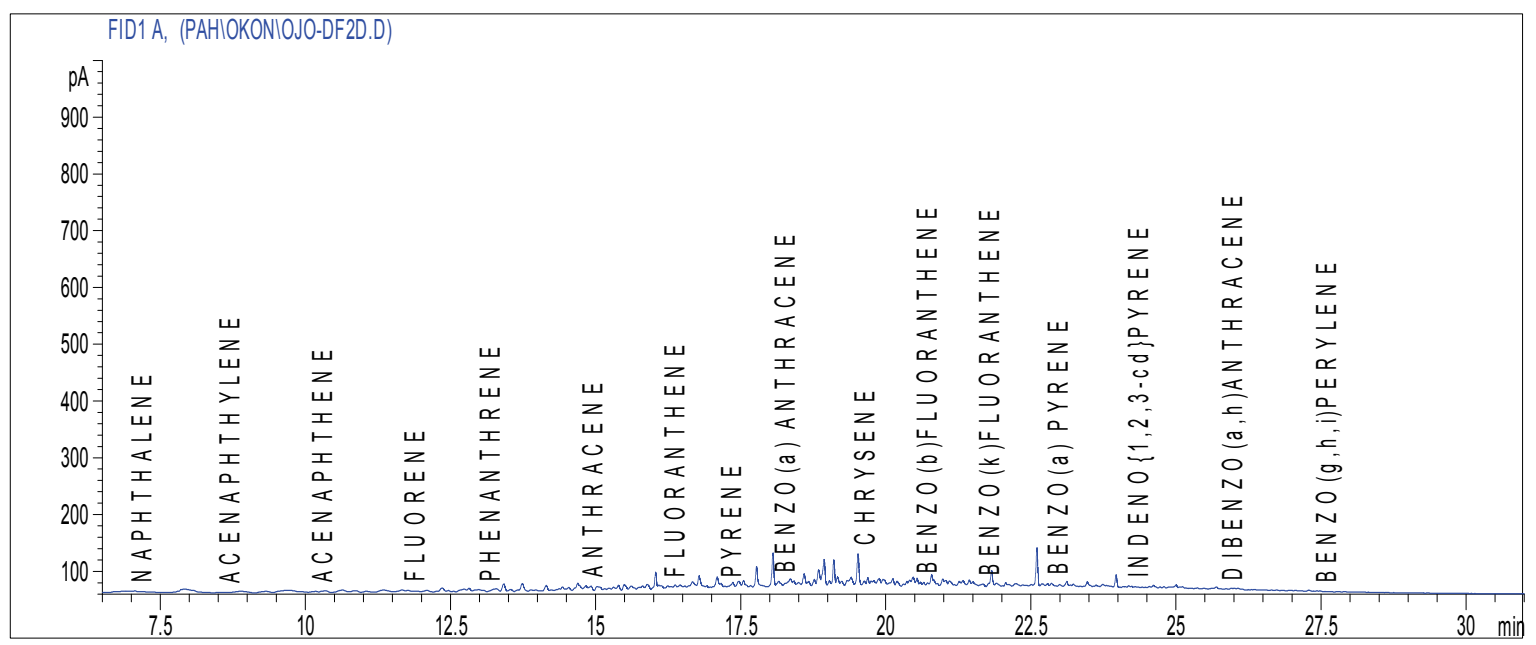

Figure 12. Chromatogram for smoked dried fish from Makurdi 


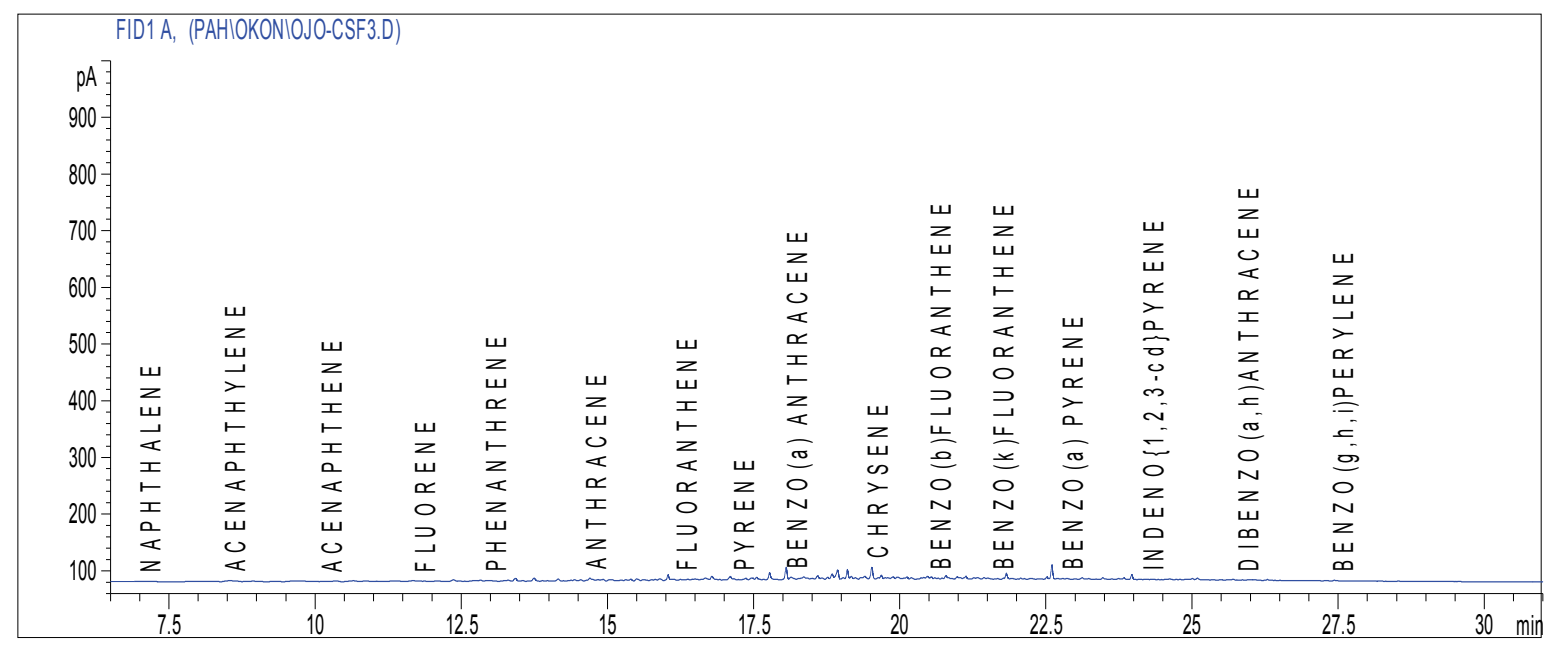

Figure 13. Chromatogram for non smoked fish 